\title{
Host Resistance to Monilinia vaccinii-corymbosi in Flowers and Fruits of Highbush Blueberry
}

Jeffrey S. Lehman and Suzu Igarashi, Department of Life and Earth Sciences, Otterbein College, 155 West Main Street, Westerville, OH 43081; and Peter V. Oudemans, Rutgers University, Blueberry and Cranberry Research and Extension Center, Lake Oswego Rd., Chatsworth, NJ 08019

\begin{abstract}
Lehman, J. S., Igarashi, S., and Oudemans, P. V. 2007. Host resistance to Monilinia vacciniicorymbosi in flowers and fruits of highbush blueberry. Plant Dis. 91:852-856.

Monilinia vaccinii-corymbosi, the causal agent of mummy berry disease, infects blueberry flowers via the gynoecial pathway. To describe the expression of host resistance in highbush blueberry (Vaccinium corymbosum), fungal growth in the styles and colonization of the locules were compared among five blueberry cultivars in a series of controlled greenhouse experiments. Styles were harvested 1 and 4 days postinoculation, and the length colonized by hyphae was determined using fluorescence microscopy. At 8 weeks after inoculation, fruit were harvested and scored for the presence of hyphae in the locules. The infection frequency of styles ranged from 0.33 to 0.71 , and only cv. Weymouth had significantly lower infection frequency than the other cultivars. The mean length of the colonized portion of the stylar canal ranged from 0.126 to $0.434 \mathrm{~mm}$ after 1 day and 1.62 to $3.59 \mathrm{~mm}$ after 4 days. Hyphae in the styles of cv. Weymouth exhibited the least growth, whereas hyphae in the styles of cultivars Jersey and Rancocas were significantly longer. The distance of style penetrated for cultivars Bluecrop and Coville was intermediate. The mean disease incidence of locules differed significantly. Values for cultivars Weymouth and Jersey were the smallest (0.038 and 0.039) and largest (0.249 and 0.236), respectively. The results demonstrate that a component of resistance to infection by M. vacciniicorymbosi is expressed during growth in the gynoecial pathway.
\end{abstract}

Additional keywords: fruit mummification, fruit rot

Highbush blueberry (Vaccinium corymbosum) is a long-lived perennial crop with a high market value. Production in New Jersey averages $7,600 \mathrm{~kg} / \mathrm{ha}$ with a value of approximately $\$ 27,000$ per hectare. Fungal diseases cause a significant portion of the crop loss experienced by growers. Mummy berry (Monilinia vacciniicorymbosi (Reade) Honey) and anthracnose (Colletotrichum acutatum Simmonds ex Simmonds) are the two major fruit diseases affecting this host and are the primary targets for the majority of fungicide applications in New Jersey (Dean Polk, State IPM Agent, Chatsworth, NJ, personal communication). Although these diseases may be effectively controlled with fungicide applications, there are economic, health, and environmental reasons for reducing pesticide inputs.

Mummy berry disease occurs in commercial and native stands of Vaccinium spp. throughout North America $(9,10)$ and has recently been reported in Europe (8). The disease reduces fruit production by

Corresponding authors:

Jeffrey Lehman: jlehman@otterbein.edu

Peter Oudemans: oudemans@ aesop.rutgers.edu

Accepted for publication 3 January 2007.

doi:10.1094/PDIS-91-7-0852

(C) 2007 The American Phytopathological Society blighting newly formed vegetative and flower buds (primary infection phase) or by causing a hard rot of the fruit (secondary infection phase) $(10,28)$, rendering the fruit unfit for commercial use or resulting in the assignment of lower quality grades (22).

The primary infection phase is initiated in the spring when pseudosclerotia germinate and produce apothecia from which ascospores are discharged. Windblown ascospores infect the breaking buds and young elongating shoots of blueberry hosts (Vaccinium spp.), resulting in blighted host tissues bearing conidia $(20,21)$. Heritable, genetic variation among fungal populations for apothecium development has been demonstrated and appears to coincide with variation in host ontogeny $(12,14)$. The degree of synchronicity between timing of host susceptibility and pathogen infectivity based on apothecium and ascospore production has been used to predict host resistance due to disease avoidance (13).

In the secondary infection phase, conidia are deposited on stigmatic surfaces of open flowers by insects or wind $(2,29)$. The germ tubes grow into the ovary via the stylar canal, traversing the same path as the pollen tubes $(16,24,29)$. Hyphae reach the ovary 4 to 7 days after inoculation, initially entering the locules before invading the fruit mesocarp $(16,18,24)$. Mycelia stromatize at later stages of development, resulting in formation of pseudosclerotia $(1,16,24)$. Mummified fruit fall to the ground where they serve as survival structures $(3,29)$.

Resistance to both the primary and secondary phases of the disease has been identified (4-7,17,19,25-28); however, results of these studies often vary across environments and do not completely agree. Most studies to date have utilized a common garden experimental design where various host genotypes and local pathogen strains are grown together in field plots to evaluate the blueberry germplasm for susceptibility to both the primary and secondary infection. The results are frequently confounded by differences in host phenology such as the developmental rate of vegetative shoots or the timing and duration of flower susceptibility. Understandably, rankings of cultivars using this type of experimental design tend to produce variable results. Stretch and Ehlenfeldt (25) compared the response of 68 cultivars and selections to floral infection by $M$. vaccinii-corymbosi in a controlled, common garden experiment over a 3-year period. In addition to changes in cultivar rankings due to interseason variations, a considerable range in disease incidence was reported among cultivars. There are many possible explanations for the observed differences, including differences in isolate virulence, relative attractiveness of cultivars to pollinators, and differences in host cultivar phenology, as well as difference in host resistance. Stretch et al. (27) have compared accessions from seven wild populations of diploid species of blueberry with six isolates of $M$. vaccinii-corymbosi. They identified high levels of resistance in accessions of $V$. boreale, $V$. myrtilloides, $V$. pallidum, $V$. tenellum, and $V$. darrowi. Neither Stretch and Ehlenfeldt (25) nor Stretch et al. (27) directly addressed or described the expression of resistance during the infection process.

This study was undertaken to quantitatively describe the growth of $M$. vacciniicorymbosi in the styles and fruits of five cultivars of highbush blueberry. Specifically, we wanted to: (i) determine when during pathogenesis (i.e., stylar growth, locular invasion) resistance to conidial infection is expressed, and (ii) compare five common highbush blueberry cultivars for resistance to stylar infection, hyphal 
growth in styles, fruit infection, and locule colonization. Currently, floral infection by M. vaccinii-corymbosi is managed with repeated applications of fungicides during the bloom period (23). A clearer understanding of the expression of resistance during pathogenesis may aid in the development of disease-resistant cultivars and offer an alternative or supplement to chemical control of the disease. We propose that the number of colonized locules-a form of disease severity that is the culmination of resistance to ovary colonization-is a useful measure of host resistance to $M$. vaccinii-corymbosi. It is relatively easy to measure and therefore can be incorporated into the process of cultivar selection by breeders. An abstract summarizing preliminary results of this study has been published (11).

\section{MATERIALS AND METHODS}

Cultivars of Vaccinium corymbosum. Resistance in highbush blueberry was studied in five widely planted North American cultivars-Jersey, Coville, Rancocas, Bluecrop, and Weymouth. Jersey (PI 554808) is a late-maturing cultivar derived from a cross of Rubel $\times$ Grover and released in 1928. Both parents were wild plants collected in NJ. Coville (PI 554829) is a late-ripening cultivar derived from the cross GM-37 (Jersey $\times$ Pioneer $) \times$ Stanley and released in 1949. It has the same parentage as cultivar Dixie (not used in this study). Bluecrop (PI 554885) is a widely grown, midseason cultivar derived from GM-37 (Jersey $\times$ Pioneer) $\times$ CU-5 (Stanley $\times$ June). It was released for commercial planting in 1952. Weymouth (PI 554823) is an early-ripening cultivar derived from June $\times$ Cabot and released in 1936. Rancocas (PI 554816) is an early midseason cultivar derived from (Brooks $\times$ Russell) $\times$ Rubel that was released in 1926.

Production of conidia. M. vacciniicorymbosi sporulates very poorly in culture; therefore, we obtained sufficient quantities of conidia for artificial inoculations from ascospore-infected shoots produced in the greenhouse. Germinating pseudosclerotia of $M$. vaccinii-corymbosi were collected from a commercial blueberry field near Chatsworth, NJ, and placed on moist sand. Pseudosclerotia were maintained at $15^{\circ} \mathrm{C}$ with a 12 -h photoperiod in a growth chamber and allowed to develop apothecia with ascospores. Ascospores that were actively discharged from mature apothecia were collected onto glass coverslips placed directly on top of open apothecia. The ascospores were stored on coverslips at $5^{\circ} \mathrm{C}$ until they were used in artificial inoculations. Prior to inoculations, ascospores were washed from the coverslips with water, counted with a hemacytometer, and diluted to $2 \times 10^{5}$ spores $/ \mathrm{ml}$. Ascospore viability, which was determined by counting the number of germinated spores on potato dextrose agar (PDA), was $56 \%$.
Dormant branches (75 cm length) were clipped from field-grown plants of cultivar Jersey prior to budbreak. The dormant cuttings were brought into the greenhouse at $15^{\circ} \mathrm{C}$ with a 12 -h photoperiod and placed in water to initiate budbreak and shoot elongation. Breaking buds (5 to 20 $\mathrm{mm}$ in length) were wound-inoculated with a suspension of $2 \times 10^{5}$ ascospores $/ \mathrm{ml}$ by placing a $10-\mu$ d drop on the elongating bud and piercing the tissue with a hypodermic needle. The cuttings were moved to a dark mist chamber at $15^{\circ} \mathrm{C}$ for 2 days and then to the greenhouse at $\sim 15^{\circ} \mathrm{C}$. After 2 weeks, conidia were vacuumed from the surfaces of sporulating, diseased shoots with a Cyclone Surface Sampler (Burkard Manufacturing Co. Ltd., England). Dry conidia were mixed with roughly equal amounts of fresh pollen collected from cultivar Rancocas or Jersey and used in artificial inoculation studies.

Artificial inoculation of blueberry cultivars. Dormant 2- and 3-year-old plants of cultivars Jersey, Coville, Rancocas, Bluecrop, and Weymouth in 3-liter pots were brought into the greenhouse at $\sim 15^{\circ} \mathrm{C}$ to initiate budbreak and the formation of flowers. Newly opened flowers from the five cultivars were simultaneously inoculated and pollinated by applying dry conidia ( 20 to 40 spores per flower) and blueberry pollen ( $\sim 20$ to 40 grains per flower) from cultivar Jersey to the stigma of attached flowers with a finely tipped glass rod. A total of 101 to 430 flowers per treatment was inoculated. Subsets of flowers were then harvested on days 1 and 4 . Another subset was allowed to develop to immature fruits and was harvested 8 weeks after inoculation. On days 1 and 4 after inoculation, corollas were removed from the detached flowers and pistils were fixed overnight at room temperature in a solution containing $10 \%$ formalin, $8 \%$ glacial acetic acid, $50 \%$ ethanol, and $32 \%$ distilled water $\left(\mathrm{dH}_{2} \mathrm{O}\right)$ per volume. Following fixation, pistils were rinsed twice in sterile $\mathrm{dH}_{2} \mathrm{O}$ before clearing and further fixation for $2 \mathrm{~h}$ at $60^{\circ} \mathrm{C}$ in $0.3 \%$ trichloroacetic acid dissolved in a $3: 1 \mathrm{vol} / \mathrm{vol}$ mixture of $95 \%$ ethanol and chloroform. Pistils were then rinsed at least twice in sterile $\mathrm{dH}_{2} \mathrm{O}$. Styles were detached from the ovaries and then softened in $8 \mathrm{M}$ sodium hydroxide for 20 min at $60^{\circ} \mathrm{C}$. For microscopic examination, styles were stained in $0.1 \%$ decolorized methyl blue (CI 42780) in $0.1 \mathrm{M} \mathrm{K}_{3} \mathrm{PO}_{4}$ ( $\mathrm{pH} 12$ ) and then rinsed twice in $\mathrm{dH}_{2} \mathrm{O}$. Styles were detached from the ovaries, split open longitudinally on a glass microscope slide, and observed for fungal growth with an American Optical Series 20 microscope outfitted with epifluorescence (American Optical, Buffalo, NY) with a Chroma 31000 filter set (Chroma Technology Corp., Rockingham, VT) (excitation filter 300 to $400 \mathrm{~nm}$, barrier filter $400 \mathrm{~nm}$, emitter filter 410 to $500 \mathrm{~nm}$ ). The presence/absence of fungal growth in the style below the stigma at day 1 after inoculation was recorded and used to determine infection frequency of styles. The distance hyphae had penetrated the stylar canal was measured with an ocular micrometer, and the average distance and standard error of colonization at days 1 and 4 after inoculation were calculated. Immature fruit collected at 8 weeks after inoculation were cut in half horizontally and examined macroscopically for the presence of white mycelium or stromata in the locules of the fruit. Fruits were considered infected if they contained the diagnostic, compact hyphae in any of the locules. Disease incidence was calculated based on the number of infected fruits per total number of set fruits. The number of infected locules ( 0 to 5) was also recorded as an indicator of disease severity.

Experimental design and statistical analysis. Artificial inoculation experiments were conducted twice over a 2-year period (1995 to 1996) during the flowering period of blueberries. Differences among cultivars were compared for mean infection frequency of styles at day 1 after inoculation, mean distance of style penetrated at days 1 and 4, mean disease incidence of fruit 8 weeks after inoculation, and number of infected locules per fruit. For the dependent variable infection frequency of styles, each experiment was a completely random design with five blueberry cultivars and five replications. Each replication was comprised of 17 to 41 styles. For the dependent variable of mean distance of style penetrated, each experiment was a completely random design with five or three blueberry cultivars for analysis of days 1 and 4 after inoculation, respectively. For both infection frequency of styles and mean distance penetrated at days 1 and 4, data from the separate experiments were combined, and analyses were performed on means for cultivars averaged across replications within each experiment. The mean square for the experiment $x$ cultivar interaction was used to test for significance of the effect of cultivar. Significant differences among cultivar means were determined with StudentNewman-Keuls mean separation tests $(\alpha=$ 0.05).

In the analyses of disease incidence of fruits, each experiment was analyzed as a completely random design with five or three blueberry cultivars and three replications with 349 to 601 and 94 to 329 fruits per replication for experiments 1 and 2, respectively. In the analyses of number of infected locules, each experiment was analyzed as a completely random design with five or three blueberry cultivars and three replications with 15 to 186 and 10 to 30 fruits per replication for years 1 and 2, respectively. For all analyses, treatment differences were determined with StudentNewman-Keuls mean separation tests $(\alpha=$ 0.05). 


\section{RESULTS}

Fungal conidia and blueberry pollen deposited on the stigmatic surface of newly opened flowers germinated and grew into the stylar canal within $24 \mathrm{~h}$. Under UV fluorescence microscopy, pollen tubes and fungal hyphae appeared pale greenish to greenish-yellow (Fig. 1A) and were distinguishable based on the presence of callose plugs and hyphal cross walls/septa (Fig. 1B). Pollen tubes displayed callose plugs periodically throughout the length of the tube. In contrast, fungal hyphae displayed highly defined cross walls which delineated cells. At days 1 and 4 after deposition of conidia and pollen, hyphae and pollen tubes were easily distinguishable. All styles included in the study displayed at least 10 pollen grains on the stigmatic surface. At 8 weeks following inoculation, hyphal growth in the locules of fruits was easily detectible and appeared as a tough, white, hyphal mass in the locular cavity (Fig. 1C). The mass was defined by walls of the ovary, and locules could be readily categorized as infected or not.

Stylar infections. The infection frequency of styles differed significantly among cultivars $(P=0.0001)$ and ranged from 0.33 to 0.71 . Based on mean separation tests, the infection frequency of styles of cultivar Weymouth was significantly less than those of the other cultivars (Table 1). The infection frequencies of the other cultivars were statistically the same. The mean distance of style penetrated differed significantly among blueberry cultivars on day $1(P=0.0003)$ and day $4(P=0.0004)$ after inoculation. On day 1 , the mean length of hyphae ranged from 0.126 to $0.434 \mathrm{~mm}$ among the five cultivars (Table 1). Fungal hyphae found in the styles of cultivar Weymouth were significantly shorter than hyphae found in the other cultivars. The mean length of hyphae found in cultivars Jersey and Rancocas were 3.4 and 3.2 times longer, respectively. The distance of style penetrated for cultivars Bluecrop and Coville were of intermediate length. On day 4, the mean lengths of styles colonized for Jersey and Bluecrop were 2.2 and 1.4 times greater, respectively, than those for Weymouth (Table 1).

Fruit infections. The mean disease incidence of fruits examined at 8 weeks after inoculation with $M$. vaccinii-corymbosi differed significantly among cultivars $(P=$ 0.002 and $P=0.001$ for experiments 1 and 2 , respectively). In both experiments, the mean infection frequencies for cultivars Weymouth and Jersey were the smallest (0.038 and 0.039) and largest (0.249 and 0.236 ), respectively (Table 2). Values for cultivars Bluecrop, Coville, and Rancocas were intermediate. Similarly, the mean number of infected locules per fruit differed significantly among cultivars $(P=$ 0.003 and $P=0.0001$ for experiments 1 and 2, respectively). As with disease incidence, cultivars Weymouth and Jersey exhibited the smallest and largest values for number of infected locules, respectively, in both experiments (Table 2). In the second experiment, however, values for Bluecrop were not significantly different from Weymouth, and Coville was not significantly different from Jersey. Cultivar Weymouth produced infected fruits with only one or two infected locules; in contrast, the distribution of the number of infected locules produced by Jersey ranged from one to five but was skewed toward five (Fig. 2). Similarly, the distribution for Bluecrop ranged from one to five but was skewed toward fewer infected locules.

\section{DISCUSSION}

Evaluation of field resistance in highbush blueberry has typically yielded variable results $(17,19,25)$. This is likely due to the many interacting factors, in addition to host resistance, that contribute to the development of this complex disease (e.g., differences in isolate virulence, relative attractiveness of cultivars to pollinators). In this study, we utilized controlled inoculations of blueberry flowers with conidia of the fungus $M$. vacciniicorymbosi and microscopic examination of fungal growth to compare the resistance in five cultivars. Four features along the path of fruit colonization were used as criteria

Table 1. Style length $( \pm \mathrm{SE})$, infection frequency of styles inoculated with Monilinia vaccinii-corymbosi, and mean distance of style penetrated of five blueberry cultivars at days 1 and 4 after inoculation

\begin{tabular}{|c|c|c|c|c|}
\hline \multirow[b]{2}{*}{ Cultivar } & \multirow{2}{*}{$\begin{array}{l}\text { Style length } \\
(\mathrm{mm})^{\mathrm{y}}\end{array}$} & \multirow{2}{*}{$\begin{array}{c}\text { Infection } \\
\text { frequency }^{x}\end{array}$} & \multicolumn{2}{|c|}{ Mean distance of style penetrated $(\mathrm{mm})^{x}$} \\
\hline & & & Day 1 & Day 4 \\
\hline Weymouth & $7.2 \pm 0.15$ & $0.33 \mathrm{~b}^{\mathrm{z}}$ & $0.126 \mathrm{~d}$ & $1.62 \mathrm{c}$ \\
\hline Bluecrop & $8.5 \pm 0.16$ & $0.71 \mathrm{a}$ & $0.289 \mathrm{c}$ & $2.24 \mathrm{~b}$ \\
\hline Coville & $8.8 \pm 0.07$ & $0.67 \mathrm{a}$ & $0.361 \mathrm{~b}$ & $\ldots$ \\
\hline Jersey & $8.5 \pm 0.01$ & $0.64 \mathrm{a}$ & $0.401 \mathrm{ab}$ & $3.59 \mathrm{a}$ \\
\hline Rancocas & $7.3 \pm 0.01$ & $0.58 \mathrm{a}$ & $0.434 \mathrm{a}$ & $\ldots$ \\
\hline
\end{tabular}

$x$ Values are the means of two separate experiments with five replications. Each replication was comprised of 17 to 41 and 20 to 41 styles for day 1 and day 4 , respectively.

y Values are the means of 40 to 50 styles.

${ }^{\mathrm{z}}$ Means within columns with a letter in common do not differ significantly at $\alpha=0.05$ based on Student-Newman-Keuls mean separation tests.

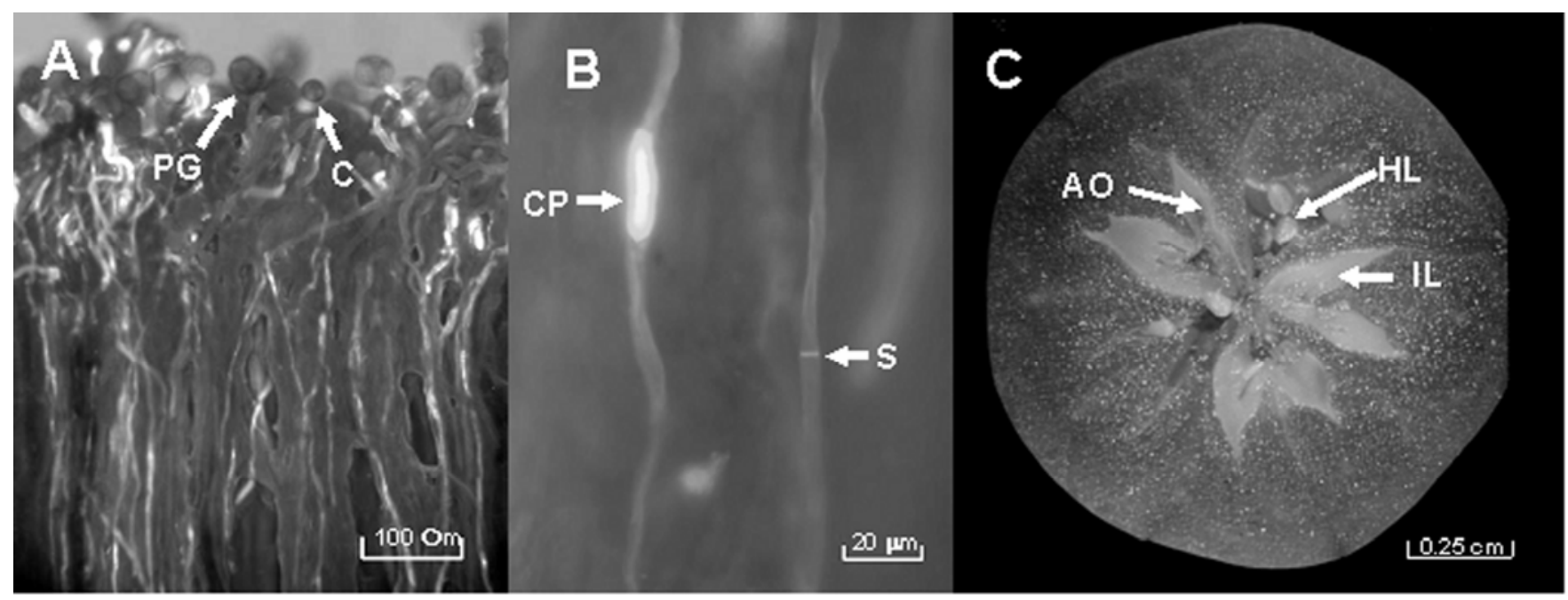

Fig. 1. Infection of blueberry flowers by Monilinia vaccinii-corymbosi. A, Longitudinal view of the stigmatic surface under UV fluorescence microscopy showing pollen grain (PG) and fungal conidia (C). B, Longitudinal view of the stylar canal under UV fluorescence microscopy showing brightly fluorescing callose plugs (CP) of the pollen tube and distinctive septa/cross walls (S) of the fungal hypha. C, Transverse sectional view of 8-week-old blueberry fruit (cv. Jersey) with five locules. Three of the five locules have been colonized and are filled with fungal mycelia. Infected locule $=\mathrm{IL}$, healthy locule $=\mathrm{HL}$, aborted ovule $=\mathrm{AO}$. 
to investigate the response of each cultivar, including: (i) frequency of stylar infection, (ii) hyphal growth in the stylar canal, (iii) locular infection, and (iv) extent of locular colonization. The major advantage of this approach over other field-based approaches for the comparison of cultivar resistance is that the host response can be evaluated with fewer confounding effects. Also, host resistance can be quantified throughout the process of ovary colonization.

The cultivars differed significantly at various stages of ovary colonization. Weymouth was the most resistant cultivar tested for all stages of infection and was also the only cultivar that showed reduced incidence of stylar infection. The other four cultivars-Jersey, Bluecrop, Coville, and Rancocus-exhibited various degrees of susceptibility throughout the infection process. The results presented in this study compare reasonably well with the rankings of cultivars reported by Stretch and Ehlenfeldt (25). For example, the cultivar Weymouth was ranked as the most resistant in both studies, while Jersey was ranked typically as being the most susceptible. Cultivars Bluecrop and Coville were considered intermediate in both studies. In contrast, our results correlated poorly with previous studies by Pepin and Toms (19) that reported Weymouth as being very susceptible. Interestingly, the cultivar Rancocas was ranked as highly susceptible by Stretch and Ehlenfeldt (25) in the first year of their study but was among the most resistant in the final 2 years. In our study, cultivar Rancocas varied in its expression of resistance to the different stages of the infection (i.e., it supported the highest rate of hyphal growth in the stylar canal but demonstrated a comparatively lower rate of infection and colonization of the locule). Based on these observations, it appears that resistance in cultivar Rancocas to infection by $M$. vaccinii-corymbosi is first expressed in the locule, and not during the infection of the stigma or style. McManus et al. (15) used a similar technique to examine the infection process of the related fungus Monilinia oxycocci (the causal agent of cottonball) on cranberries. In contrast to our findings, the authors reported no difference in resistance among the four cranberry cultivars tested.

Investigators who have compared cultivars for resistance to blighting phase and fruit infection phase of the disease frequently report that the levels are not necessarily correlated $(25,26)$. In fact, Pepin and Toms (19) report different scenarios for resistance to the two stages of mummy berry disease: (i) resistance to both stages, (ii) resistance to only one stage (blighting or floral infection) but not to the other, and (iii) no resistance to either stage. The lack of correlation between the two stages as reported in the literature suggests that modes of resistance to the two stages are unlinked and presumably act via distinct genetic mechanisms. Functionally, both types of resistance play an important function in reducing disease in the field. Control of the fruit rot phase using fungicides can be difficult since the flower target is small and ephemeral with significant turnover. In addition, multiple applications of fungicide are required to effectively treat plants throughout flowering. Resistance to floral infections could significantly reduce disease levels in areas where blight infections are difficult to manage or where the use of pesticides is not possible (i.e., wild/native areas).

Despite its resistance to secondary infection, we have observed and it has been reported (26) that cultivar Weymouth is susceptible to the primary phase of mummy berry disease. In contrast, cultivar Jersey is resistant to the primary phase (personal observation and 26) while susceptible to the secondary phase. In a monoculture, resistance to either phase will effectively break the disease cycle; however, when two or more cultivars are grown in close proximity, severe epidemics may result when susceptibility in different cultivars is complementary. The combination of Weymouth and Jersey in a common field maximizes the potential for disease. Ultimately, the combination of resistance to both infection phases in a single cultivar is most desirable for disease management.
Resistance to the secondary phase of mummy berry is very likely a quantitative trait that is significantly influenced by environmental factors. As such, incidence of fruit infection as typically measured in field studies does not provide the quantitative information required to properly measure resistance. Our research identifies the number of locules that are colonized, a form of disease severity, as a practical and useful parameter by which to measure host resistance. The number of infected locules is the culmination of germination and growth through the gynoecial pathway and is, therefore, a reliable indicator of resistance. The number of infected locules is a relatively easy feature to quantify by viewing a transverse section of immature fruit and therefore can be incorporated into the process of cultivar selection by breeders.

In conclusion, our results demonstrate that resistance to infection by $M$. vacciniicorymbosi is expressed during stylar and locular growth in the gynoecial pathway. We were able to identify and compare resistance in five commonly grown commercial cultivars during pathogenesis, including stylar infection, hyphal growth in styles, fruit infection, and locule colonization. This information will be useful to plant breeders in developing highbush blueberry cultivars with resistance to multiple stages of the secondary infection phase of mummy berry disease.

Table 2. Mean disease incidence and mean number of infected locules of five blueberry cultivars at 8 weeks after inoculation with Monilinia vaccinii-corymbosi

\begin{tabular}{llllcc}
\hline & \multicolumn{2}{c}{ Disease incidence $^{\mathrm{x}}$} & & \multicolumn{2}{c}{ Number of infected locules $^{\mathbf{y}}$} \\
\cline { 2 - 3 } \cline { 5 - 6 } Cultivar & Exp. 1 & Exp. 2 & & Exp. 1 & Exp. 2 \\
\hline Weymouth & $0.039 \mathrm{c}^{\mathrm{z}}$ & $0.038 \mathrm{~d}$ & & $1.3 \mathrm{c}$ & $1.6 \mathrm{c}$ \\
Bluecrop & $0.110 \mathrm{~b}$ & $0.106 \mathrm{c}$ & & $2.1 \mathrm{~b}$ & $2.0 \mathrm{bc}$ \\
Rancocas & $\ldots$ & $0.103 \mathrm{c}$ & & $\ldots$ & $2.3 \mathrm{~b}$ \\
Coville & $\ldots$ & $0.164 \mathrm{~b}$ & & $\ldots$ & $3.4 \mathrm{a}$ \\
Jersey & $0.249 \mathrm{a}$ & $0.236 \mathrm{a}$ & & $3.9 \mathrm{a}$ & $3.6 \mathrm{a}$ \\
\hline
\end{tabular}

${ }^{x}$ Values were calculated as the number of infected fruits divided by the total number of set fruits. Means are based on three replications with 349 to 601 and 94 to 329 fruits per replication for experiments 1 and 2 , respectively.

y Values were calculated as the mean number of locules containing hyphae for infected fruits. Means are based on three replications with 15 to 186 and 10 to 30 fruits per replication for years 1 and 2 , respectively.

${ }^{\mathrm{z}}$ Means within columns with a letter in common do not differ significantly at $\alpha=0.05$ based on Student-Newman-Keuls mean separation tests.

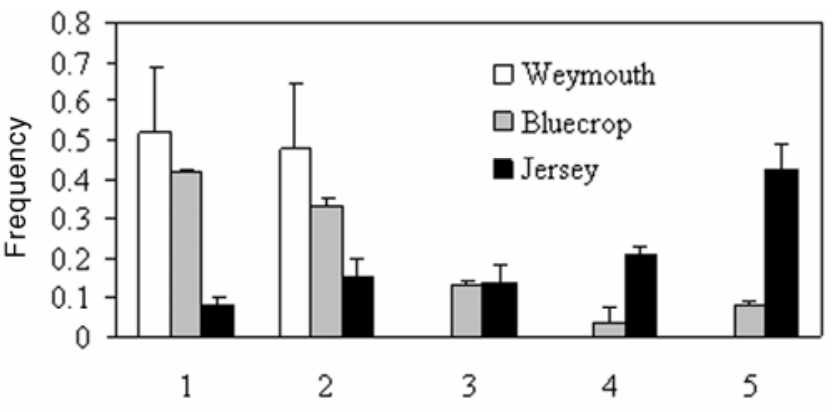

Number of locules infected with hyphae

Fig. 2. Frequency of blueberry fruits with 1 to 5 locules infected with Monilinia vaccinii-corymbosi. Values $( \pm \mathrm{SE})$ are based on two experiments with three replications with 10 to 186 fruits per replication. 


\section{LITERATURE CITED}

1. Batra, L. R. 1983. Monilinia vacciniicorymbosi (Sclerotiniaceae): Its biology on blueberry and comparison with related species. Mycologia 75:131-152.

2. Batra, L. R., and Batra, S. W. T. 1985. Floral mimicry induced by mummy berry fungus exploits host's pollinators as vectors. Science 228:1011-1013.

3. Cox, K. D., and Scherm, H. 2001. Oversummer survival of Monilinia vaccinii-corymbosi in relation to pseudosclerotial maturity and soil surface environment. Plant Dis. 85:723-730.

4. Ehlenfeldt, M. K., and Stretch, A. W. 2000. Mummy berry blight resistance in rabbiteye blueberry cultivars. HortScience 35:13261328.

5. Ehlenfeldt, M. K., and Stretch, A. W. 2001. Resistance to blighting by Monilinia vacciniicorymbosi in diploid and polyploidy Vaccinium species. HortScience 36:955-957.

6. Ehlenfeldt, M. K., Stretch, A. W., and Brewster, V. 1996. Genetic and morphological factors influence mummy berry blight resistance in highbush blueberry cultivars. HortScience 31:252-254.

7. Ehlenfeldt, M. K., Stretch, A. W., and Lehman, J. S. 1997. Shoot length affects susceptibility to mummy berry blight within highbush blueberry cultivars. HortScience 32:884-887.

8. Gosch, C. 2003. Monilinia vaccinii-corymbosi on highbush blueberries (Vaccinium corymbosum L.): Also in Europe! Eur. J. Hortic. Sci. 68:238-241.

9. Hancock, J. F., and Draper, A. D. 1989. Blueberry culture in North America. HortScience 24:551-556.

10. Hildebrand, P. D., Milholland, R. D., and Stretch, A. W. 1995. Mummy berry. Pages 1112 in: Compendium of Blueberry and Cranberry Diseases. F. L. Caruso and D. C. Ramsdell, eds. American Phytopathological Society,
St. Paul, MN.

11. Lehman, J. S., Igarashi, S., and Oudemans, P. V. 1999. Hyphal growth of Monilinia vacciniicorymbosi in blueberry. (Abstr.) Phytopathology 89:S45.

12. Lehman, J. S., and Oudemans, P. V. 1997. Phenology of apothecium production in populations of Monilinia vaccinii-corymbosi from early- and late-maturing blueberry cultivars. Phytopathology 87:218-223.

13. Lehman, J. S., and Oudemans, P. V. 1997. Phenology of the mummy berry fungus and its blueberry host: Implications for resistance breeding. Acta Hortic. 446:287-292.

14. Lehman, J. S., and Oudemans, P. V. 2000. Variation and heritability of phenology in the fungus Monilinia vaccinii-corymbosi on blueberry. Phytopathology 90:390-395.

15. McManus, P. S., Best, V. M., and Voland, R. P. 1999. Infection of cranberry flowers by Monilinia oxycocci and evaluation of cultivars for resistance to cottonball. Phytopathology 89:1127-1130.

16. Milholland, R. D. 1977. Sclerotium germination and histopathology of Monilinia vacciniicorymbosi on highbush blueberry. Phytopathology 67:848-854.

17. Nelson, J. W., and Bittenbender, H. C. 1971. Mummy berry disease occurrence in a blueberry selection test planting. Plant Dis. Rep. 55:651-653.

18. Ngugi, H. K., Scherm, H., and Lehman, J. S. 2002. Relationships between blueberry flower age, pollination, and conidial infection by Monilinia vaccinii-corymbosi. Phytopathology 92:1104-1109.

19. Pepin, H. S., and Toms, H. N. W. 1969. Susceptibility of highbush blueberry varieties to Monilinia vaccinii-corymbosi. Phytopathology 59:1876-1878

20. Ramsdell, D. C., Nelson, J. W., and Myers, R. L. 1974. An epidemiological study of mummy berry disease of highbush blueberry. Phytopathology 64:222-228.

21. Ramsdell, D. C., Nelson, J. W., and Myers, R. L. 1975. Mummy berry disease of highbush blueberry: Epidemiology and control. Phytopathology 65:229-232.

22. Scherm, H., and Copes, W. E. 1999. Evaluation of methods to detect fruit infected by Monilinia vaccinii-corymbosi in mechanically harvested rabbiteye blueberry. Plant Dis. 83:799-805.

23. Scherm, H., and Stanaland, R. D. 2001 Evaluation of fungicide timing strategies for control of mummy berry disease of rabbiteye blueberry in Georgia. Small Fruits Rev. 1(3):69-81.

24. Shinners, T. C., and Olson, A. R. 1996. The gynoecial infection pathway of Monilinia vaccinii-corymbosi in lowbush blueberry (Vaccinium angustifolium). Can. J. Plant Sci. 76:493497.

25. Stretch, A. W., and Ehlenfeldt, M. K. 2000 Resistance to the fruit infection phase of mummy berry disease in highbush blueberry cultivars. HortScience 35:1271-1273.

26. Stretch, A. W., Ehlenfeldt, M. K., and Brewster, V. 1995. Mummy berry disease blight resistance in highbush blueberry cultivars. HortScience 30:589-591.

27. Stretch, A. W., Ehlenfeldt, M. K., Brewster, V., Vorsa, N., and Polashock, J. 2001. Resistance of diploid Vaccinium spp. to the fruit rot stage of mummy berry disease. Plant Dis. $85: 27-30$

28. Varney, E. H., and Stretch, A. W. 1966. Diseases and their control. Pages 236-279 in Blueberry Culture. P. Eck and N. F. Childers, eds. Rutgers University Press, New Brunswick, NJ.

29. Woronin, M. 1888. Uber die sclerotienkrankheit der vaccinieen-beeren. Mem. Acad. Imp Sci. St. Petersbourg, VII:36(6):1-49. 